\title{
Strong and Weak Resultatives in Chinese Resultative Constructions*
}

\author{
Xiaowen Zhang \\ Huaiyin Institute of Technology, Huaian of Jiangsu, China
}

\begin{abstract}
Washio (1997) contrasts resultative constructions in English and Japanese in terms of strong and weak resultatives and proposes that both strong and weak resultatives are allowed in English while only weak ones are acceptable in Japanese. When strong and weak resultatvies are examined in two types of Chinese resultative constructions: resultative V-A-(NP) compounds and V-DE-(NP)-A constructions, it can be found that both strong and weak resultatives are allowed in resultative $\mathrm{V}-\mathrm{A}-\mathrm{NP})$ compounds while only strong ones are acceptable in V-DE-(NP)-A constructions. Why so? It is related to the function of DE and this question can be explained in terms of the syntactic structures of strong and weak resultatives in Chinese based on Folli's three-layer system.
\end{abstract}

Index Terms — resultative constructions, strong and weak resultatives, Folli's three-layer system

\section{INTRODUCTION}

Researching on resultative constructions has become a hot topic in linguistic field in recent years, because it plays an important role in illuminating the nature of lexical semantics and its relationship with syntax. Resultative constructions refer to clauses in which, in addition to the main verb $(\mathrm{V})$, there is a secondary predicate known as the result phrase (XP), consisting of an adjective phrase (AP) or preposition phrase (PP) or V (V-V compounds in Japanese and Chinese). This XP refers to the state described by AP or PP holds of the noun phrase as the result of the action denoted by the verb. For example:

(1) a. John watered the tulips flat.

b. He broke the vase into pieces.

c. John sha-si le Mary. (Chinese)

John kill-dead ASP Mary

'John killed Mary dead.'

(1a) means that the metal became flat because of John's hammering it, and (1b) means that the vase went to pieces because he broke it. (1c) means that Mary was dead because John killed her. From these sentences, it is observed that they emphasize the description of a state that results from the action rather than simply describe the action typically denoted by the main verb.

The following parts will discuss resultative constructions in English, Japanese and Chinese in details.

\section{A. English Resultative Constructions}

English resultative constructions can be syntactically divided into two major classes according to their main verbs: transitive and intransitive. In transitive resultatives, the subject causes the object NP to undergo a change and the word order of this type is $\mathrm{S} V \mathrm{O}$ AP/PP, where $\mathrm{S}$ and $\mathrm{O}$ are abbreviations of $\mathrm{NP}_{1}$ and $\mathrm{NP}_{2}$, respectively. For example:

(2) a. He hammered the metal flat.

(Washio 1997, p. 6)

b. The horses dragged the logs smooth. $\quad$ (Washio 1997, p. 6)

Example (2a) means that the metal became flat because of his hammering it, and (2b) means that the log became smooth because of the horse's dragging it.

There is another special type of transitive resultative constructions in English, in which the postverbal NP is not necessarily the logical object of the main verb. A "dummy object" must be inserted in this construction, so that the word order of this type is superficially the same as transitive ones, i.e. S V O AP/PP, as shown in (3).

(3) a. Mary ran herself tired.

b. John danced his feet sore.

c. She worked herself sick.

In (3), the adjective specifies the state of the entity described by the object NP as a result of the action described by the main verb. But because main verbs are intransitive in their basic uses, their syntactic objects in these resultatives are not the actual object of the main verb. For example, in (3c), Washio (1997) argues that she doesn't work 'herself'. In (3c), the usage of the main verb involves more than the simple activity of working.

\footnotetext{
* This paper serves for the Program of Philosophy and Social Science Research in Colleges and Universities of Jiangsu Province (Number: 2019SJA1652; Title: <A Contrastive Study of Resultative Constructions in Chinese, Japanese and English>).
} 
In intransitive resultatives, NP is the subject of the resultative construction and the sentence denotes a change of state, and the word order of this type is $\mathrm{NP}_{1} \mathrm{~V}$ AP/PP. For example:

(4) The lake froze solid.

In (4), freeze is an unaccusative verb. The simplified D-structure of (4) is shown in (5). This sentence states that the lake became solid because of freezing.

(5) $\underline{e}$ froze the lake solid.

In general, there are these three types of resultative constructions in English, but compared with resultative constructions in Chinese and Japanese, it can be found that there are only few resultative V-V compounds in English, which will not be discussed in the paper.

\section{B. Japanese Resultative Constructions}

There are two distinct syntactic structures in Japanese resultative constructions based on Washio (1997), as in (6).
(6) a. $\mathrm{S}$
$\mathrm{O}$
$\left[\mathrm{v} \mathrm{V}_{1}-\mathrm{V}_{2}\right]$
b. $\mathrm{S}$
O ATP V

In (6), in addition to RVCs, Japanese permits only certain types of transitive resultative constructions, in which the result predicate is an adjective. Here ATP represents 'adjective-type phrase', which has the same function with AP in English resultatives, but ATP is not a simple adjective. Some examples are shown in (7).
(7) a. Kare-ga John-o uti-korosi-ta.
He-NOM John-ACC shoot-kill-PAST
'He shot John dead.'
b. Kare-wa kabe-o siroku nut-ta.
He-TOP wall-ACC white paint-PAST
'He painted the wall white.'

(6a) shows a resultative V-V compound, illustrated by (7a). In Japanese, $V_{2}$ is the head of the entire verb (see (Kageyama, 1993)), while $\mathrm{V}_{1}$ describes a simple activity. In (7b), ATP siroku is an inflected form of siroi 'white', a word classified as 'Adjective' in Japanese grammar.

\section{Chinese Resultative Constructions}

There are two types of Chinese resultative constructions discussed in the paper, that is, resultative V-C-(NP) compounds and V-DE-(NP)-C constructions. Here, $\mathrm{C}$ is the abbreviation of Complement, which can be V or A. Let me use a tree diagram to make clear of the relations between two types of Chinese resultative constructions, as shown in $(8)$.

(8)

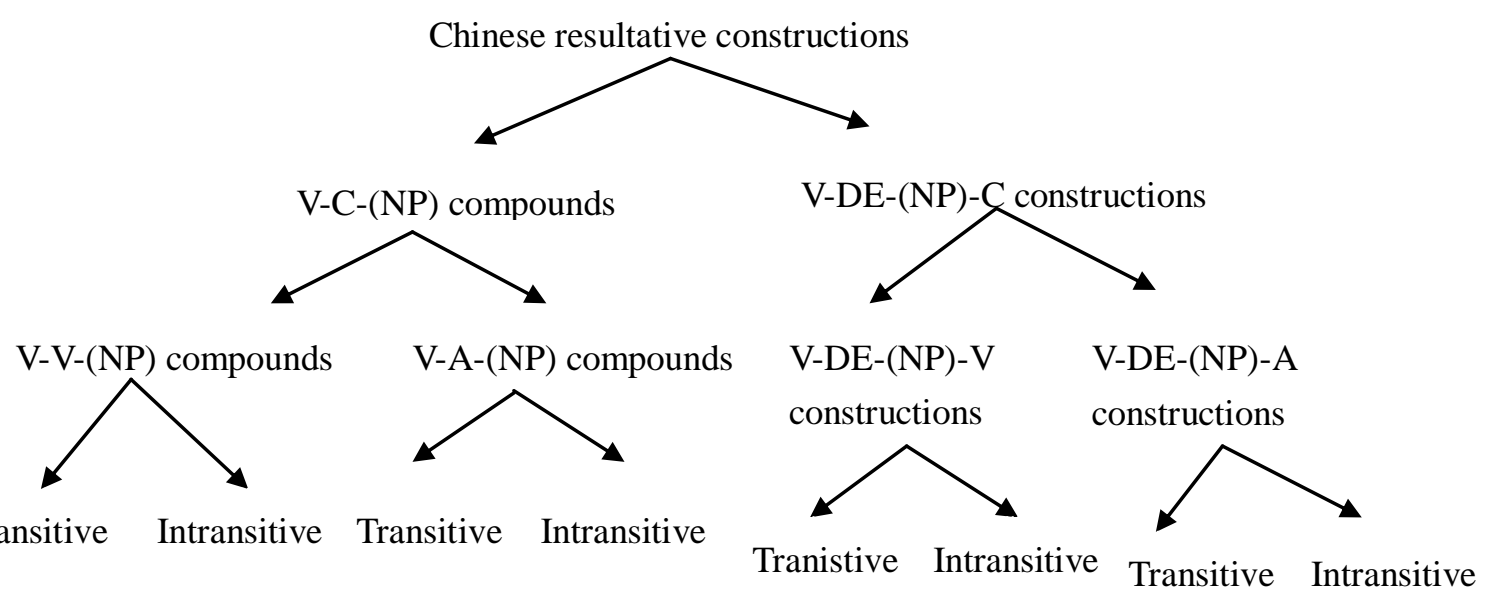

The diagram (8) shows the specific division of two types of Chinese resultative constructions, and examples are illustrated in (9).

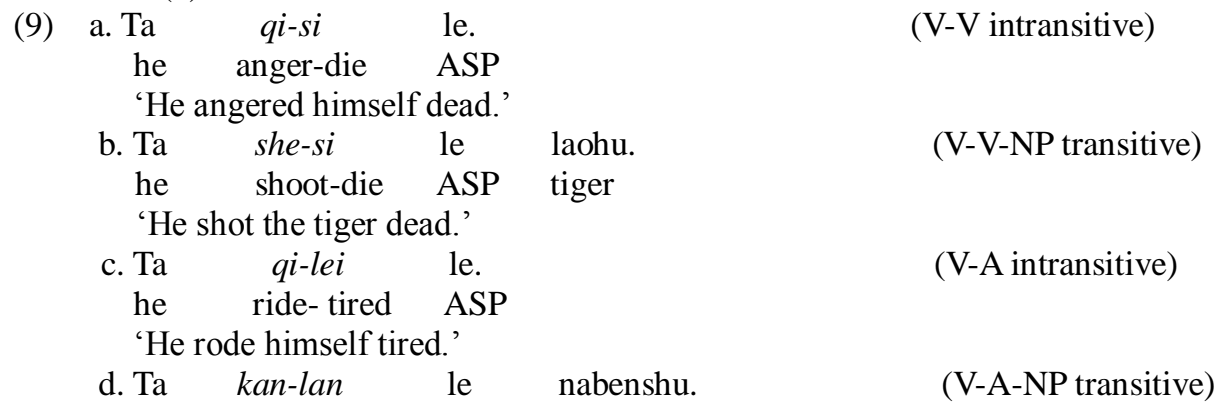


he see-broken ASP that book

'He read that book so frequently that it was broken'

e. Mary qi de yaoyaqiechi.

Mary anger DE gnash the teeth

'Mary gnashed her teeth with rage.'

f. Mary qi de wo yaoyaqiechi.

Mary anger DE me gnash the teeth

'Mary angered me gnashing my teeth.'

g. Mary kan de hen lei.

Mary read DE very tired

'Mary read very tired.'

h. John kan de na ben shu dou po le. (V-DE-NP-A transitive)

John read DE that CL book even broken ASP

'John read that book till that book became broken.'

The resultative V-V-(NP) compound in (9b) is constructed by compounding two verbal morphemes, with $\mathrm{V}_{1}$ she 'shoot' indicating a causing event and $\mathrm{V}_{2}$ si 'dead' indicating the resulting event. The resultative V-A-(NP) compound in (9d) is constructed by compounding two morphemes: a verbal one and an adjectival one, the verb kan 'see' indicating a causing event and the adjective lan 'broken' indicating the resulting event. The V-DE-(NP)-V construction in (9f) is also constructed by two verbal morphemes, with $\mathrm{V}_{1}$ qi 'anger' denoting the cause and $\mathrm{V}_{2}$ yaoyaqiechi 'gnash the teeth' denoting the result. The V-DE-(NP)-A construction in (9h) is constructed by a verbal morpheme kan 'see' and an adjectival one po 'broken'. In ( $9 \mathrm{f}$ and $\mathrm{h}$ ), $\mathrm{V}_{1}$ and $\mathrm{V}_{2} / \mathrm{A}$ are separated by DE and the postverbal object wo 'myself' and nabenshu 'that book', whereas without the postverbal object, $\mathrm{V}_{1}$ and $\mathrm{V}_{2} / \mathrm{A}$ are only separated by DE, as in (9e and $\mathrm{g}$ ).

Chinese resultative constructions are not only divided into two basic types: with DE and without DE, but also the result phrase in these constructions is subdivided into two types: the verb and the adjective. In the paper, the pair of the resultative V-A-(NP) compound and the V-DE-(NP)-A construction is mainly discussed in details by contrasting with Japanese and English ones.

\section{Washio's Strong and Weak Resultative Analysis}

Washio (1997) contrasts English and Japanese resultative constructions in terms of the meaning of the main predicate, i.e., strong and weak resultatives and proposes that both strong and weak resultatives are allowed in English while only weak resultatives are acceptable in Japanese.

Strong resultatives refer to those ones in which the meaning of the verb and the meaning of the adjective are independent of each other. In resultatives of this type, it is impossible to predict from the semantics of the verb what kind of state the patient comes to be in as the result of the action named by the verb. For example:

(10) a. John hammered the metal flat.

b. Mary danced her feet sore.

In (10a), the verb hammer doesn't imply any state of the patient that might result from the action it names. In (10b), the verb dance is unergative, so it cannot contain, in its lexical semantics, anything like the notion sore denoted by the adjective that is predicated of the 'fake object'. Thus, examples in (10) are strong resultatives.

Weak resultatives are those ones in which the meaning of the verb entails the meaning of the adjective. In other words, in weak resultatives, if the states of the patients change, verbs imply that they would change in certain fixed directions to reach the final states. For example: (from (Washio, 1997))

(11) a. John dyed the dress pink.

b. I froze the ice cream solid.

c. He painted the wall white.

In (11a), the verb dye doesn't contain the notion pink, but it clearly contains the notion 'color'. Thus, the adjective pink is not completely independent of the verb dye. In (11b), the notion solid is closely related to the meaning of freeze. In (11c), the meaning of the verb paint entails the change of the wall's color; the adjectival result phrase white denotes the result. Thus, examples in (11) are weak resultatives. From examples in (10) and (11), it can be said that both strong and weak resultatives are allowed in English.

Compared with English resultative constructions, only weak resultatives are allowed in Japanese. For example:

(12) a. * John-ga kinzoku-o petyanko-ni tatai-ta.

John-NOM metal-ACC flat pound-PAST

'John pounded the metal flat.'
b. *Mary-ga asi-o itaku odotsu-ta.
Mary-NOM foot-ACC sore dance-PAST

'Mary danced her feet sore.'

$\begin{array}{llcc}\text { c. Mary-ga } & \text { doresu-o } & \text { pinku-ni } & \text { some-ta. } \\ \text { Mary-NOM } & \text { dress-ACC } & \text { pink } & \text { dye-PAST }\end{array}$

'Mary dyed the dress pink.'

d. Watasi-wa aisukurimu-o katikati-ni koorase-ta. 


I-TOP the ice cream-ACC solid
'I froze the ice cream solid.'
$\begin{array}{llll}\text { e. Kare-wa } & \text { kabe-o } & \text { siroku } & \text { nu-ta. } \\ \text { He-TOP } & \text { wall-ACC } & \text { white } & \text { paint-PAST } \\ \text { 'He painted the wall white.' } & \end{array}$

(12a-b) are strong resultatives, so the corresponding resultative constructions in Japanese are not allowed, since Japanese only permits weak resultatives. (12a) is a transitive resultative, in which the verb hammer can be interpreted as the verb tataku 'pound' in Japanese. The verb tataku 'pound' doesn't imply any state of the patient that might result from the action it names. (12b) is an intransitive resultative, in which the verb dance is a unergative verb, the object her feet is a dummy object. In Japanese, there are no intransitive resultatives. In (12c-d-e), main verbs dye, freeze and paint entail the meaning of the respective result predicates the color, solid and white, so they are weak resultatives. Thus, they are also grammatical in Japanese.

Washio (1997) analyzes the situations of English and Japanese resultatives in terms of strong and weak resultatives, but not touching Chinese resultative constructions. In section 2, strong and weak resultatives are discussed in two types of Chinese resultative constructions by contrasting with English and Japanese resultative constructions.

\section{Strong And WeAK Resultatives in Chinese}

In this section, strong and weak resultatives are examined in resultative V-A-(NP) compounds and V-DE-(NP)-A constructions, respectively. Depending on the definitions of strong and weak resultatives, huge examples are found in Chinese to show that both strong and weak ones are allowed in resultative V-A-(NP) compounds while only strong ones are acceptable in V-DE-(NP)-A constructions.

\section{A. Strong and Weak Resultatives in Resultative V-A-(NP) Compounds}

Like in English, both strong and weak resultatives are allowed in Chinese resultative V-A-(NP) compounds, as shown in (13).

(13) Strong resultatives in V-A-(NP) compounds
a. Na tiao gou fei-xing le wo baba.
that CL dog bark-awake ASP my father

'That dog barked my father awake.'

*So-no inu-wa watasi-no qiqi-o hoe-okosi-ta.

that dog my father bark-awake

b. Zhangsan chui-bian le jinshupian.

Zhangsan hammer-flat ASP the metal

'Zhangsan hammered the metal flat.'

*Zhangsan-wa metaru-o taira-ni tatai-ta.

Zhangsan metal flat pound-ed

(14) Weak resultatives in V-A-(NP) compounds
a. Ta tu-bai-le qiang.
He paint-white-ASP wall
'He painted the wall white.'
Kare-ga kabe-o siroku nut-ta.
$\mathrm{He}$ wall white paint
b. John dong-ying-le bingqiling.
John freeze-solid-ASP the ice cream
'John froze the ice cream solid.'
John-wa aisukurimu-o katikati-ni koorase-ta.
John ice cream solid freeze

$(13 \mathrm{a}, \mathrm{b})$ are strong resultatives, and it can be observed that they are allowed in Chinese resultative V-A-(NP) compounds but not in Japanese. (14a, b) are weak resultatives, and they are allowed both in resultative V-A-(NP) compounds and Japanese. Based on examples in (13-14), it can be said that both strong and weak resultatives are acceptable in Chinese resultative V-A-(NP) compounds.

Moreover, resultative V-A-(NP) compounds are productive in Chinese. Some strong resultatives are grammatical in Chinese, while they are ungrammatical in English, as shown in (15).
(15) a. Lisi chi-huai le
duzi.
Lisi eat-bad ASP stomach

'Lisi has eaten (something bad or too much, as a result he has an) upset stomach.

*Lisi ate his stomach bad.

*Lisi-wa onaka-o tabe-koware-ta.

Lisi stomach eat-bad

b. John ti-po le qiuxie. 


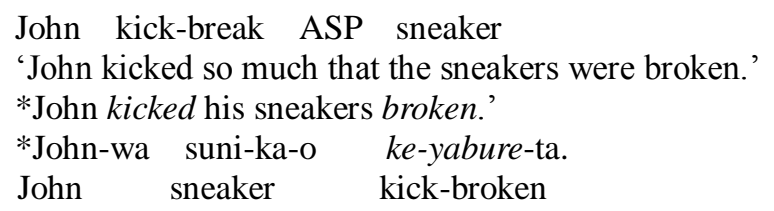

$(15 \mathrm{a}, \mathrm{b})$ cannot be acceptable in English and Japanese, while they are grammatical in Chinese. In (15b), as Cheng and Huang (1994) points out, qiuxie 'sneaker' is not the object of V $t i$ 'kick'. What John kicked is a football, not his sneakers. In this case, V $t i$ 'kick' functions like an intransitive verb. This indicates that Chinese allows some wider range of strong resultatives, the reason of which still remains a mystery. I leave it open here.

\section{B. V-DE-(NP)-A Constructions Are Strong Resultatives}

Now let us consider the situation of V-DE-(NP)-A constructions, based on Washio's strong and weak resultative analysis. Strong resultative readings are allowed in V-DE-(NP)-A constructions, but weak resultative variants are ungrammatical, as shown in (16).

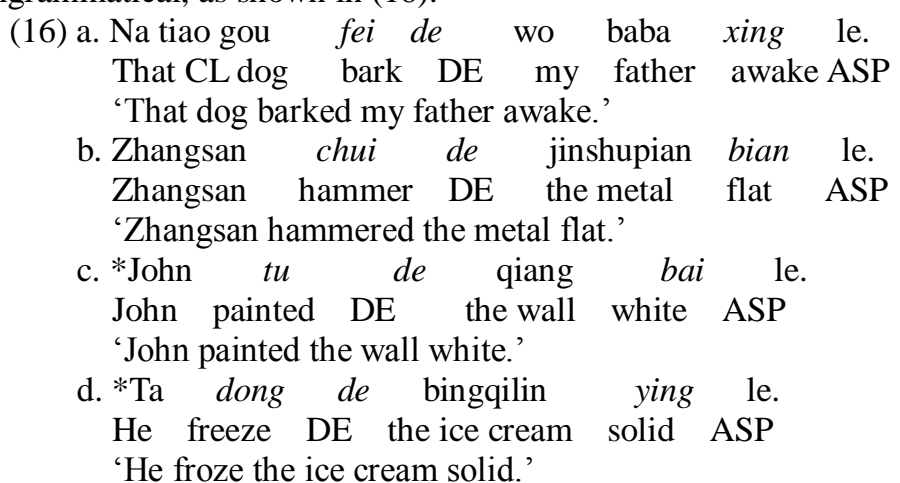

In $(16 \mathrm{a}, \mathrm{b})$, the adjective xing 'awake' and bian 'flat' are not implied by the verb fei 'bark' and chui 'hammer', namely, they are strong resultatives. $(16 \mathrm{a}, \mathrm{b})$ indicate that strong resultatives in V-DE-(NP)-A constructions are grammatical. In $(16 \mathrm{c}, \mathrm{d})$, the adjectives bai 'white' and ying 'solid' are implied by the verbs $t u$ 'paint' and dong 'freeze', and the sentences are ungrammatical. Thus, weak resultatives in V-DE-(NP)-A constructions are not allowed. By contrast, both strong and weak resultatives are accepted in Chinese resultative V-A-(NP) compounds, this sharp difference must be noted.

More examples of Chinese ungrammatical weak resultatives in V-DE-(NP)-A constructions are shown in (17).

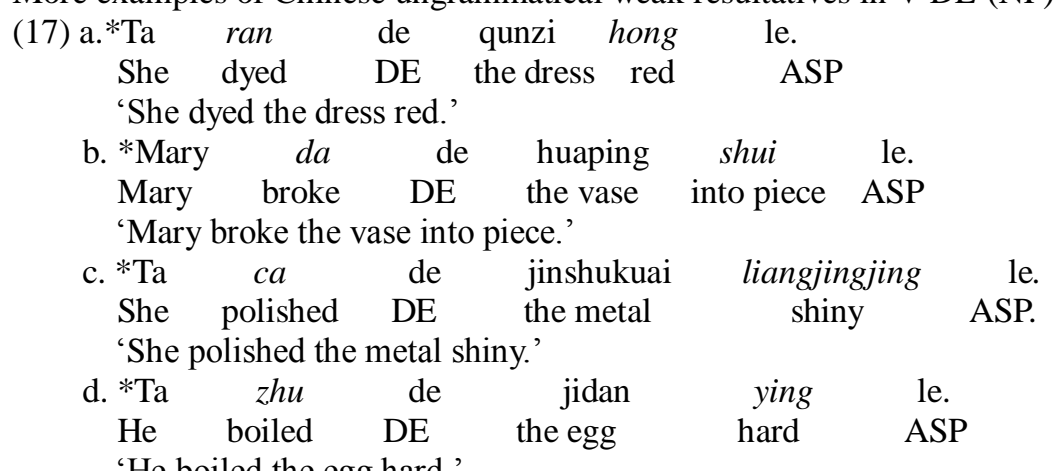

A natural question to ask here is: why weak resultatives in V-DE-(NP)-A constructions are not acceptable. In section 3, I will examine this question depending on Folli's (2001) analysis: the cause, the process and the result, and Lin's (2003) analysis of DE as a process.

\section{V-DE-(NP)-A CONSTRUCTION IN CHINESE AS STRONG RESULTATIVES}

Not weak but strong resultatives are allowed in Chinese V-DE-(NP)-A constructions. Why so? In weak resultatives, the main verb directly entails the meaning of the result predicate, that is, it seems to be possible that the appearance of DE makes weak V-DE-(NP)-A constructions ungrammatical. Thus, it becomes necessary to discuss the function of DE in Chinese resultative constructions at first.

\section{A. The Function of DE in Chinese Resultative Constructions}

In Chinese modern linguistics, there are some main explanations of DE in Chinese resultative constructions, such as: Li's (2009) proposal of V-DE as a phonological word; Li's (1998) proposal of DE as a preposition; Dai's (1992) proposal of DE as a derived suffix; Sybesma's (1999) proposal of DE as a degree word, and so on. These explanations, however, have their own shortcomings, for instance, in Chinese V-DE-(NP)-A constructions, when V-DE is a 
phonological word, here the main verb V must be an intransitive word, which is not suitable for the transitive verbs; when DE is a preposition, it never takes a nominal complement but always takes a sentential complement; when DE is a derived suffix which can change the argument structure of the matrix verb or the predicate and it adds an additional XP complement to the predicate, ungrammatical sentences will be produced, in which the extra NP can be inserted between the main verb and DE.

As to the function of DE in resultative V-DE-(NP)-A constructions, in the paper, based on Folli (2001) and Lin (2013), DE can be indicated as a Process. Specifically, Folli (2001) claims that in addition to the causing and resultative events, there is an intermediate event denoting a process in resultative constructions. Thus, it can be said that a resultative construction has three semantic layers, that is, the cause, the process and the result, which Folli claims to be reflected in syntactic structure, as shown in the following tree diagram.

(18)

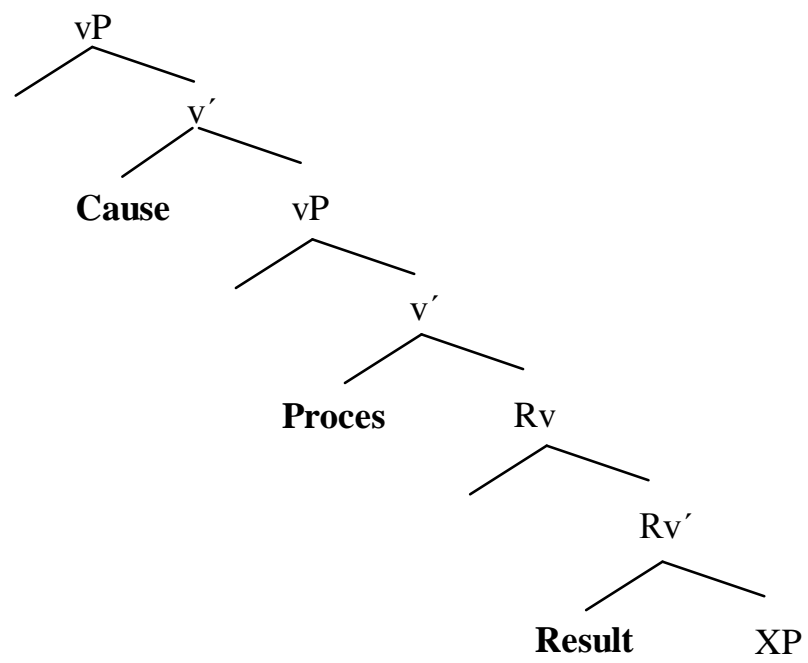

One piece of evidence is provided by Folli that the process should be separated from the cause and the result, exemplified by (19).

(19) He rolled the ball to the wall very fast.

a. He very quickly rolled the ball so that it reaches the wall. (cause)

b. He pushed the ball so that it rolls to the wall very fast. (process)

c. He pushed the ball to the wall as a result it rolls very fast. (result)

In (19), Folli argues the adverbial word (fast, quickly) modifies different parts of a complex event. When it modifies the cause, the sentence means that his action of causing the ball to roll was very fast. When it modifies the rolling process, the sentence means that the action of the ball rolling was very fast before reaching the wall. When it modifies the result, the sentence means that his action of rolling the ball to the wall made the ball roll very fast. As Folli (2001) points out, given that the cause, the process, and the result of the action can be modified, it is reasonable to postulate that these three subevents should be separated in the syntactic structure, as in (18).

Lin (2003) adopts Folli's analysis to Chinese resultative constructions and proposes that DE is a process head in V-DE-(NP)-A constructions. An example from Lin is given to illustrate his own proposal, such as (20).

(20) Wo qi de toupi fa ma.

I angry DE scalp get numb

'I was angry to the point that my scalp got numb.'

In (20), the fact that I was angry to the extent that my scalp became numb. DE indicates a process in which anger leads to the physical (scalp-becoming-numb) reaction.

Lin's analysis of DE as a process head is reasonable, because Hein \& Kuteva (2002) propose that the English verb get or obtain often grammaticalizes to mean the process of change cross linguistically. DE in Chinese actually means 'get' or 'obtain', as in (21).

(21) Zhe ci kaoshi, wo de le 100 fen.

this CL examination, I got ASP 100 marks

'I got 100 marks in this examination.'

Here, I would like to adopt Lin's analysis of DE as a process, indicating the change of state, and suggest that it can explain the reason for the lack of weak resultatives in V-DE-(NP)-A constructions, which, to my knowledge, passed unnoticed so far.

\section{B. The Lack of Weak Resultatives in V-DE-(NP)-A Constructions}

Let us consider a pair of examples in Chinese V-DE-(NP)-A constructions at first, as in (22).
(22) a. Ta
de shoupa
shi-le.
(strong ) 
He cry DE handkerchief wet-ASP

'He cried to an extent as a result that the handkerchief was wet.'

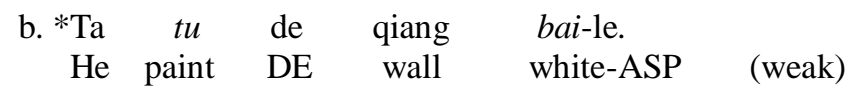

'He painted the wall white.'

The examples in (22) show that strong resultatives are acceptable in V-DE-(NP)-A constructions, while weak ones are not allowed, as in (22b). Why so? This question is not only related to the function of DE but also to the syntactic structures of V-DE-(NP)-A constructions.

Based on Folli's (2001) three-layer system, Lin (2003) proposes that DE can be denoted as a process in Chinese resultative constructions. I associate Folli's system with Lin's proposal here and illustrate the structural schema of the V-DE-(NP)-A construction in Chinese, as in (23).

(23) The syntactic structure of the V-DE-(NP)-A construction in Chinese

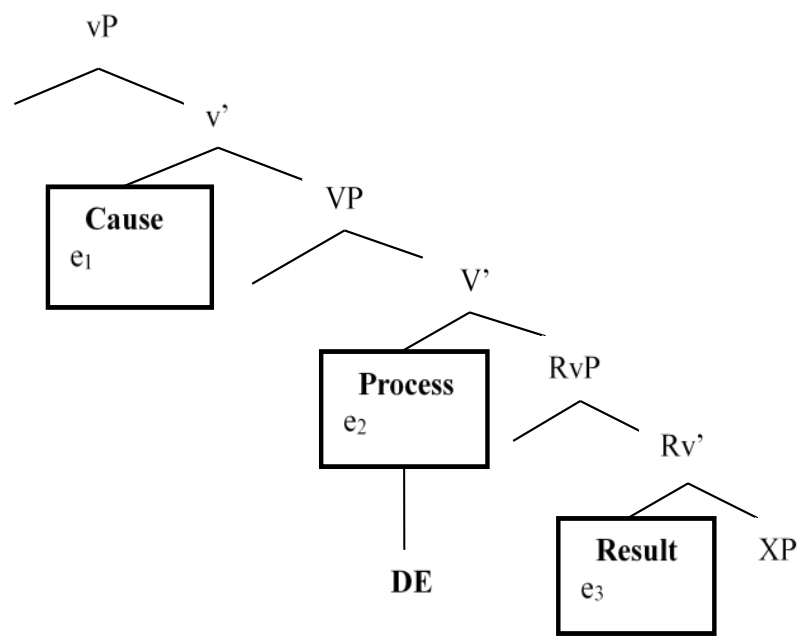

In (23), $e_{1}$ refers to a subevent expressing the cause denoted by the head verb V. $e_{2}$ represents a process denoted by DE. DE is a process that introduces an additional subevent, which is independent of $e_{1}$. And $e_{3}$ is a subevent expressing the result denoted by the result predicate, the adjective (A) in Chinese V-DE-(NP)-A constructions.

1. The Syntactic Structures of Weak Resultatives in Chinese

As to the syntactic structures of weak resultatives in English, Baker's (2003) proposes that the main verb V and the result predicate AP work together to describe the resulting state of the event, as illustrated in (24).

(24) John wiped the table clean.

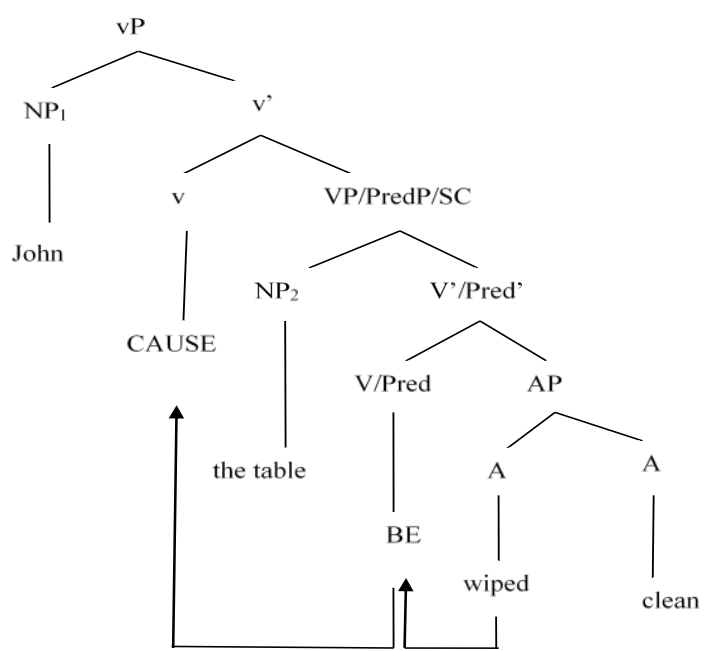

The sentence (24) can be analyzed as [vP John CAUSE [VP the table BE [wiped clean] ] ]. Baker (2003) claims that the verb wiped has an adjectival nature, which makes the verb $B E$ occupy the predicate position of the SC. And then the verb wipe rises to the predicate position of the SC, and the adjective clean is an adjunct to it. In weak resultatives, the meaning of the verb entails the meaning of the adjective, it thus can be said that the adjective can be incorporated into the verb to form a word. In (24), the verb wipe can bound with the adjective clean to form the compound wiped-clean. It seems that the verb wiped has an adjectival nature, but not all verbs in weak resultatives have this property, such as the verb paint. And I consider that X may be more suitable for representing the verb wipe and here X lacks the categorical nature. 
Baker's proposal, however, shows that the close relationship between the main verb and the result predicate, which gives evidence to the two-layer (Cause, Result) system assumption based on Folli's three-layer system.

Consider weak resultatives. In them, I repeat, the meaning of $\mathrm{V}$ entails the meaning of the result predicate A. Thus, subevent $e_{1}$ would entail the meaning of the result of subevent $e_{3}$ in (23). If so, subevent $e_{2}$, representing the process, is unnecessary in weak resultative V-DE-(NP)-A constructions, the meaning of V directly entails the meaning of the result phrase A, i.e. the appearance of subevent $e_{1}$ directly implies the appearance of subevent $e_{3}$ representing the result, without the assistance of DE. For example:

(25) a. Ta ran-hong-le qunzi.

She dye-red-ASP dress

'She dyed the dress red.'

b. *Ta ran de qunzi hong-le.

She dye DE dress red-ASP

'She dyed the dressred.'

In (25a), subevent $\mathrm{e}_{1}$ ran 'dye' can entail the meaning of subevent $\mathrm{e}_{3}$ hong 'red', subevent $\mathrm{e}_{1}$ thus can incorporate with subevent $\mathrm{e}_{3}$ and form the V-A compound ran-hong 'dye-red'. If DE appears, as in (25b), the sentence becomes ungrammatical. DE blocks the incorporation of subevent $\mathrm{e}_{1}$ with subevent $\mathrm{e}_{3}$ in weak resultatives. Thus, I propose that it seems to be only two layers, i.e. Cause and Result allowed in weak resultatives based on Folli's (2001) three-layer system. The syntactic structures of (25) are shown in (26).

$\begin{array}{llr}\text { (26a) Ta } & \text { ran-hong-le } & \text { qunzi. } \\ \text { She } & \text { dye-red-ASP } & \text { dress }\end{array}$

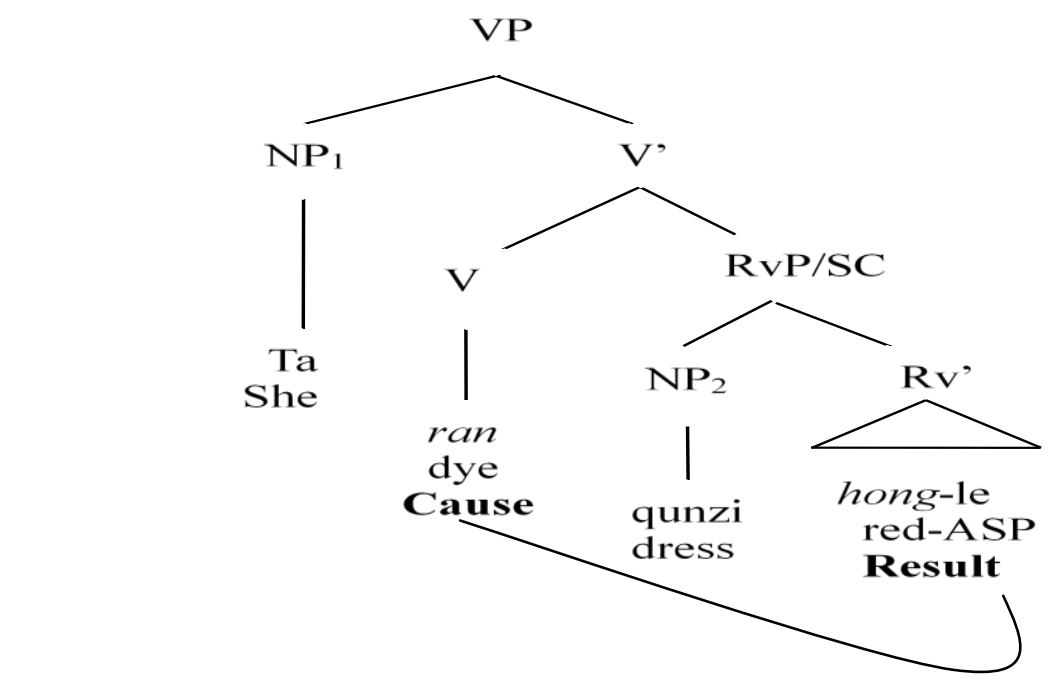

(26b) * Ta ran de qunzi hong-le.

She dye DE dress red-ASP

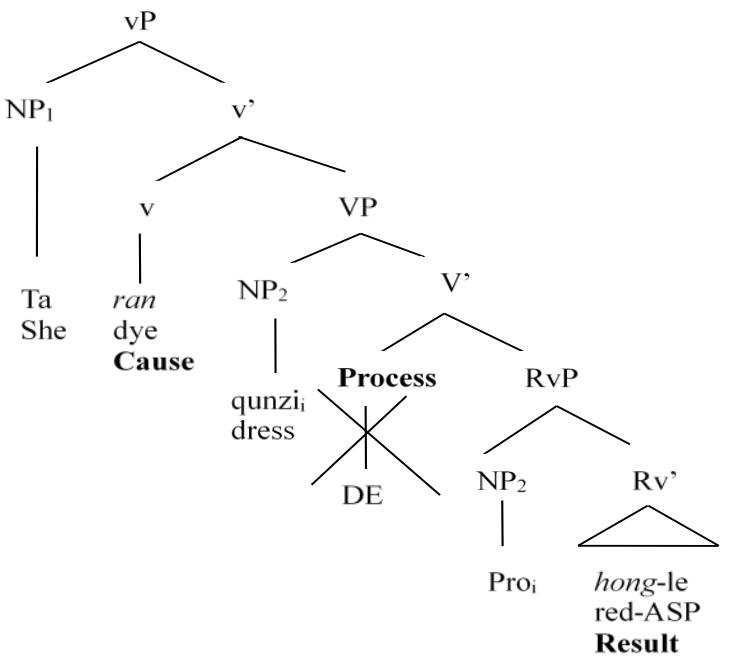

In (26a), the meaning of the main verb ran 'dye' entails the meaning of the result predicate hong 'red', in which the place of the main verb represents Cause $e_{1}$ and the place of the result predicate represents Result $e_{3}$, that is, the meaning 
of the subevent $e_{3}$ has a close relationship with the meaning of the subevent $e_{1}$. In other words, the result predicate hong 'red' can be moved to the place of the main verb ran 'dye' to form a compound. If so, the additional subevent $\mathrm{e}_{2} \mathrm{DE}$ denoting the process is unnecessary in weak resultatives.

On the other hand, Sybesma (1999) proposes that all elements in the small clause (SC) should be moved out to form a complete sentence, because the SC is not an actual sentence, without tense. In (26a), the result predicate hong 'red' is moved to the place of the main verb ran 'dye' to compose the V-A compound and the post-verbal NP qunzi 'dress' is moved to the place of the object of the main verb to assign a case. Thus, my two-layer proposal is reasonable for the syntactic structures of weak resultative V-A-(NP) compounds.

In (26b), however, the appearance of DE results in the ungrammaticality of the sentence. In weak resultatives, on one hand, the additional subevent $\mathrm{e}_{3} \mathrm{DE}$ is not allowed, because it can block the close relationship between the main verb and the result predicate in their meanings. On the other hand, Sybesma (1999) claims that if DE appears in Chinese resultative constructions, the elements in the SC have no necessity to be moved out, because the post-DE SC is a complement sentence, with tense. And she proposes that the subject of the SC can be represented by a pronoun (Pro) which is referential with the object of the main verb, as in (26b). If so, the result predicate cannot be moved to the place of the main verb and then the close relationship between them will be broken. Therefore, weak V-DE-(NP)-A constructions are ungrammatical in Chinese.

2. The Syntactic Structures of Strong Resultatives in Chinese

In V-DE-(NP)-A constructions, DE appears in the position of Process based on the tree diagram (23), assuming that the process DE in $\mathrm{e}_{2}$ serves to add a subevent, that is, DE serves as the head of an additional and independent subevent when its meaning cannot be implied by the meaning of the main verb $\mathrm{V}$ in $\mathrm{e}_{1}$. If so, it can be said that DE is the marker of strong resultatives in Chinese, as shown in (28).

(28) Zhangsan $k u$ de shoupa shi le.

Zhangsan cry DE handkerchief wet ASP

'Zhangsan cried to an extent as a result the handkerchief was wet.'

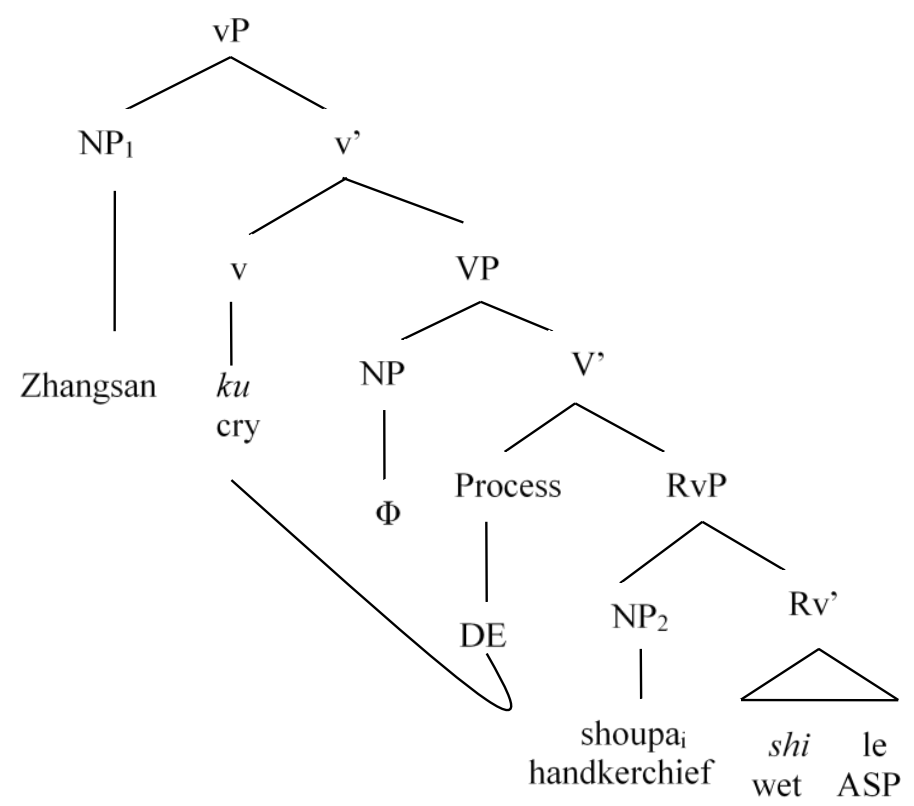

In (28), the main verb $\mathrm{V} k u$ 'cry' cannot clearly entail the meaning of the result phrase shi 'wet', and here it is necessary to demand a function word representing the process to associate the meanings of the subevent $\mathrm{e}_{1}$ and the subevent $e_{3}$, that is DE in (23).Thus, the appearance of DE is required in strong V-DE-(NP)-A constructions, because it can add a subevent to associate the meaning of $\mathrm{e}_{1}$ with $\mathrm{e}_{3}$.If no DE appears, the sentence (28) will be ungrammatical, as in (29).

(29) *Zhangsan ku shoupa shi le.

Zhangsan cried handkerchief wet ASP

'Zhangsan cried as a result the handkerchief got wet.'

I have proposed the two-layer system to illustrate the syntactic structure of the weak resultative V-A-(NP) compound in Chinese based on Folli (2001), as in (26a). It is necessary to discuss the syntactic structure of the strong resultative V-A-(NP) compound here, because the definition of strong resultatives is different from weak ones. In strong resultatives, the meaning of the main verb does not entail the meaning of the result predicate, namely, the result predicate cannot be incorporated into the main verb to form a word. I thus assume that there is a covert verb denoting the Process in the syntactic structure of the strong resultative V-A-(NP) compound. For example: 


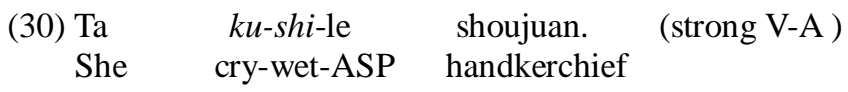

'She cried as a result that the handkerchief got wet.'

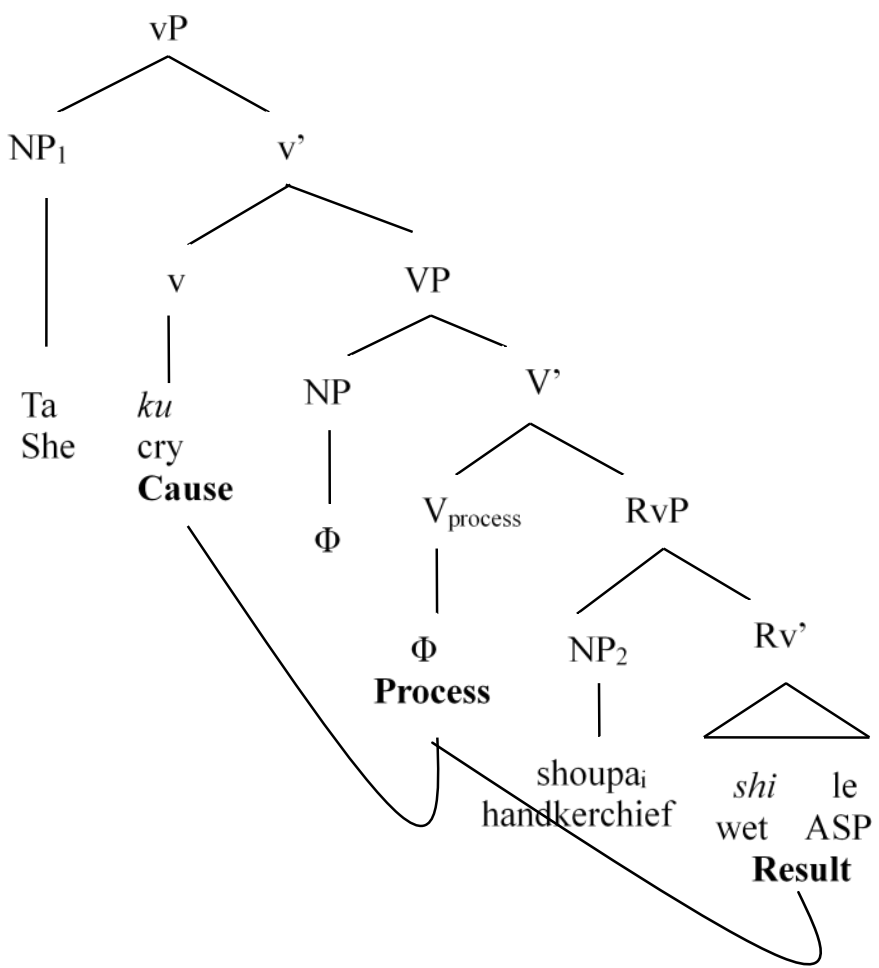

In (30), I assume that there is a null verb denoting a Process in strong resultative V-A-(NP) compounds to link the meaning of the result phrase with the meaning of the main verb. And the main verb $k u$ 'cry' is an intransitive verb which cannot followed by an object, the subject of the SC thus is located in its own position. But the result predicate denoting the Result in the $\mathrm{SC}$ is moved to the place of the covert $\mathrm{V}_{\text {process }}$ at first and then together moved to the place of the main verb $k u$ 'cry' to form a compound, since the $\mathrm{V}_{\text {process }}$ is a null verb. Compared (26a) with (30), it can be said that the syntactic structure of the weak resultative V-A-(NP) compound can be analyzed by my proposal of the two-layer system, i.e. Cause and Result, while this two-layer system cannot be suitable for the syntactic structure of the strong one. And the syntactic structure of the strong resultative V-A-(NP) compound must be analyzed based on Folli's three-layer system, that is, Cause, Process and Result, in which Process can associate the meanings of Cause and Result.

Section 3 has accounted for the question why only strong resultatives are allowed in Chinese V-DE-(NP)-A constructions, which is related to the function of DE and the syntactic structures of strong and weak resultatives. In this section, based on Folli (2001) and Lin (2003), the proposal that DE is indicated as a Process is adopted and then according to Folli's three-layer system, the two-layer system is assumed to illustrate the syntactic structures of weak resultatives in Chinese and a covert $\mathrm{V}_{\text {process }}$ is assumed to illustrate the syntactic structures of strong resultative $\mathrm{V}$-A-(NP) compounds.

\section{CONCLUSION}

The paper has introduced types of resultative constructions in English, Japanese and Chinese. Washio (1997) contrasts resultative constructions in English and Japanese in terms of strong and weak resultatives, based on which strong and weak resultatives are examined in two types of Chinese resultative constructions: resultative V-A-(NP) compounds and V-DE-(NP)-A constructions. It can be found that both strong and weak resultatives are allowed in resultative V-A-(NP) compounds while only strong ones are acceptable in V-DE-(NP)-A constructions. The paper analyzes the reason why so from the perspectives of the function of DE and the syntactic structures of strong and weak resultatives in Chinese. As to the function of DE in Chinese resultatives, Lin's (2003) proposal is adopted that DE is indicated as a Process referring to the change of state, based on Folli's (2001) three-layer system. Under the premise of $\mathrm{DE}$ as a Process, the two-layer system is suitable for illustrating the syntactic structures of weak resultatives in Chinese, because the meaning of the main verb has a close relationship with the meaning of result predicate in weak ones which implies there is no necessity of DE, indicating a Process. On the other hand, because the meaning of the main verb does not entail the meaning of the result predicate in strong resultatives, which implies DE, indicating a Process, becomes necessary to link the meanings of the main verb and the result predicate. Thus, the syntactic structure of Folli's three-layer system can be adopted to illustrate the syntactic structures of strong resultatives in Chinese. On the occasion of strong resultative V-A-(NP) compounds, because no DE appears, a covert $\mathrm{V}_{\text {process }}$ is assumed to locate in the position 
of DE, indicating a Process, which can link the meanings of the main verb and the result predicate. Owing to the decision of the function of DE in Chinese resultatives and the syntactic structures of strong and weak resultatives, the answer of the question why only strong resultatives are allowed in V-DE-(NP)-A constructions is easy to be understood.

The paper has dealt with the question why V-DE-(NP)-A constructions are strong resultatives in Chinese, but some questions remain unsolved in the paper, such as, the question why strong resultatives are so productive in Chinese, as in (15). In the future study, this question will be focused on.

\section{REFERENCES}

[1] Baker, Mark. (2003). Lexical categories. Verbs, nouns and adjectives. Cambridge: Cambridge University Press.

[2] Cheng, Lisa Lai-Shen, and Huang, C.-T. James. (1994). On the argument structure of resultative compounds. In Honor of William S-Y. Wang: Interdisciplinary Studies on Language and Language Change, ed. by Matthew Y. Chen and Ovid J. L. Tzeng, 187-221.Taipei: Pyramid Press.

[3] Dai, John Xiang-ling. (1992). The head in WO PAO DE KUAI. Journal of Chinese Linguistics 20, 84-119.

[4] Folli, Raffaella. (2001). Constructing Telicity in English and Italian. Ph.D. thesis, Oxford University.

[5] Hein, Bernd, and Kuteva, Tania. (2002). World Lexicon of Grammaticalization. Cambridge, UK: Cambridge University Press.

[6] Li,Yafei. (1998). Chinese resultative constructions and the uniformity of theta assignment hypothesis. In New Approaches to Chinese Word Formation: Morphology, Phonology and the Lexicon in Modern and Ancient Chinese, ed. by Jerome L. Packard, 285-310. New York:Mouton de Gruyter.

[7] Li, Yafei. (2009). The Syntax of Chinese. Cambridge, UK: Cambridge University Press, 84-85.

[8] Lin, Chienjer. (2003). Aspect is result: Mandarin resultative constructions and aspect incorporation. Proceedings of the Western Conference on Linguistics 32.437-464.

[9] Sybesma, Rint. (1999). The Mandarin VP. Dordrecht: Kluwer Academic Publisher.

[10] Washio, Ryuichi. (1997). Resultatives, compositionality and language variation. Journal of East Asian Linguistics 6, 1-49.

Xiaowen Zhang was born in Huaian, Jiangsu Province of Jiangsu, China in 1984. She received her PH.D. degree in English linguistics from Tokyo Gakugei University, Japanese in 2019.

She is currently an associate professor in the School of Foreign Languages, Huaiyin Institute of Technology, Huaian, China. Her research focuses on comparative linguistics, including English, Japanese and Chinese. 